\title{
Fluorimetric parameters for an early diagnosis of Esca disease in grapevine
}

\author{
Paolo Valentini ${ }^{1 *}$, Rita Perria $^{1}$, and Alessandra Zombardo ${ }^{1}$ \\ ${ }^{1}$ Council for Agricultural Research and Economics - Research Centre for Viticulture and Enology, viale Santa Margherita, 80 - 52100 \\ Arezzo (Italy)
}

\begin{abstract}
Esca disease is an increasingly widespread grapevine syndrome that currently has no valid remedies; it causes countless symptoms and almost always leads to plant death. The aim of this work was to develop a method for the early diagnosis of the presence of the fungal complex responsible for esca disease on leaves, through the identification of fluorimetric parameters of Photosystem II (PSII) efficiency, which can signal not yet evident physiological dysfunctions.
\end{abstract}

\section{Introduction}

It is now well known that the cause of the grapevine esca disease is due to infections on wood tissues brought on by several different fungal species: Phaeomoniella chlamydospora, Phaeoacremonium aleophilum, and Fomitiporia punctata [1-2]. Esca is considered a "disease complex" or a "complex disease" not only because it has multiple causative agents but also because the affected vines can show countless symptoms, including 1) brown wood streaking; 2) Petri's disease, affecting young vines (2-7 years); 3 ) young esca with tracheomycosis; 4) white rot, with the decay of ligneous structures; 5) esca proper (young esca plus white rot) [3], in an acute or chronic form [4].

Regardless of the modality of symptoms manifestation, almost always esca syndrome has an ominous progression, which leads to the vine death, as currently there are no valid, permitted, or decisive chemicals nor agronomic solutions [5].

This research aimed at providing winegrowers with an early diagnosis tool for the infection of esca disease, preceding symptoms manifestation, exploiting leaf chlorophyll fluorescence. It is a form of energy dissipation which correlates with the intensity of photosynthesis in the leaves, representing the absorbed light energy not used for the photosynthetic reaction [6]. An increase in chlorophyll fluorescence, therefore, indicates a partial block of water photolysis complex associated with photosystem II (PSII). It was recently discovered that the leaves of the vines affected by esca disease show a rise in chlorophyll fluorescence in specific sections of the extinction curve (in particular, between 300 and $400 \mu \mathrm{s}$ ), highlighting the appearance of a K-band [7].

For this reason, the purpose of our work was to identify, evaluating the differences between an appropriate number of leaves belonging to vines with or without esca symptoms, which specific fluorimetric parameters (Table 1) can give useful indications for predictive diagnostic purposes.

\section{Materials and methods}

The experimentation was carried out during the 2020 growing season in a 20-year-old Sangiovese vineyard located in Arezzo (Tuscany, Italy), where the vines are grafted on $\mathrm{SO} 4$ rootstock and are trained on an upward vertical shoot positioned trellis, with spur cordon pruning. The vineyard was monitored during the three previous seasons to detect esca disease symptoms, and 19 vines were identified and marked as affected. The leaves belonging to these 19 vines, respectively showing evident symptoms of esca disease or no symptoms, were screened using a Handy Pea chlorophyll fluorimeter (Hansatech instruments, UK). The leaf area to be analyzed was adapted to dark for at least 30 minutes then the leaf tissue was exposed to a saturating light pulse (duration $1 \mathrm{~s}$; intensity, $3000 \mu \mathrm{mol} \mathrm{m}^{-2} \mathrm{~s}^{-1}$; wavelength, $650 \mathrm{~nm}$ ). The output data were collected and subsequently processed using SPSS Software [8-9].

A total of 349 measurements of the fluorimetric parameters were carried out at different stages of the vine vegetative cycle, with two surveys between flowering and fruit set, two surveys at bunch closure stage, and two surveys at the beginning of veraison, during the period comprised from early June and midAugust. In particular, 122 observations were recorded on symptomatic leaves (symptomatic - SINTSI), 94 observations on the asymptomatic leaves of the same vines (asymptomatic - SINTNO), and 133 observations on the leaves of vines that did not show esca symptoms at least in the previous three years (TEST).

The data detected were normalized and subsequently subjected to Principal Components Analysis (PCA) [10]. The variables having a correlation coefficient with an absolute value greater than $85 \%$ with the first component were used for the canonical discriminant analysis, for the constitution of the MODEL model. It

\footnotetext{
Corresponding author: paolo.valentini@.crea.gov.it
} 
allowed identifying the vines having an excellent photosynthetic performance and to define the values of the fluorimetric parameters suitable for the early diagnosis of esca disease.

Table 1. Fluorimetric parameters detected.

\begin{tabular}{|c|c|}
\hline F0 & $\begin{array}{l}\text { Minimum fluorescence, when all PSII } \\
\text { reaction centres are open }\end{array}$ \\
\hline FM & $\begin{array}{l}\text { Maximum fluorescence, when all PSII } \\
\text { reaction centres are closed }\end{array}$ \\
\hline $\mathrm{Fv}$ & $\begin{array}{l}\text { Fluorescence of variable yield (FM - } \\
\text { F0) }\end{array}$ \\
\hline $\mathrm{Fv} / \mathrm{FM}$ & $\begin{array}{l}\text { The maximum photochemical efficiency } \\
\text { (quantum yield) of PSII }\end{array}$ \\
\hline $\mathrm{Fv} / \mathrm{F} 0$ & $\begin{array}{l}\text { Maximum water splitting efficiency at } \\
\text { donor side of PSII }\end{array}$ \\
\hline $\mathrm{F} 50 \mu \mathrm{s}$ & Fluorescence intensity at $50 \mu \mathrm{s}$ \\
\hline $\mathrm{F} 100 \mu \mathrm{s}$ & Fluorescence intensity at $100 \mu \mathrm{s}$ \\
\hline $\mathrm{F} 300 \mu \mathrm{s}$ & Fluorescence intensity at $300 \mu \mathrm{s}$ \\
\hline $\mathrm{Fj}$ & $\begin{array}{l}\text { Fluorescence intensity at the J-step ( } 2 \\
\text { ms) }\end{array}$ \\
\hline $\mathrm{Fi}$ & $\begin{array}{l}\text { Fluorescence intensity at the I-step ( } 30 \\
\mathrm{~ms})\end{array}$ \\
\hline $\mathrm{Vj}$ & $\begin{array}{l}\text { Relative variable fluorescence at the J- } \\
\text { step }(2 \mathrm{~ms})\end{array}$ \\
\hline $\mathrm{Vi}$ & $\begin{array}{l}\text { Relative variable fluorescence at the I- } \\
\text { step ( } 30 \mathrm{~ms})\end{array}$ \\
\hline $\mathrm{RC} / \mathrm{CS}$ & $\begin{array}{l}\text { Amount of active PSII reaction centres } \\
\text { per cross section at } t=0\end{array}$ \\
\hline Mo & $\begin{array}{l}\text { Approximated initial slope (in } \mathrm{ms}^{-1} \text { ) of } \\
\text { the fluorescence transient } V=f(t)\end{array}$ \\
\hline Vo-j & $\begin{array}{l}\text { Relative variable fluorescence at } 300 \\
\mu \mathrm{s}, \mathrm{K} \text {-band }\end{array}$ \\
\hline $\mathrm{ABS}$ & Absorption flux \\
\hline TRo & Trapped energy flux at $t=0$ \\
\hline ETo & Electron transport flux at $\mathrm{t}=0$ \\
\hline DIo & Dissipated energy flux at $\mathrm{t}=0$ \\
\hline REo/ABS & $\begin{array}{l}\text { Quantum yield for the reduction of end } \\
\text { acceptors of PSI per photon absorbed }\end{array}$ \\
\hline PIABS & $\begin{array}{l}\text { Performance index (PI) on absorption } \\
\text { basis }\end{array}$ \\
\hline PITOT & $\begin{array}{l}\text { Total PI, measuring the performance up } \\
\text { to the PSI end electron acceptors }\end{array}$ \\
\hline Area & $\begin{array}{l}\text { Total complementary area between } \\
\text { fluorescence induction curve and } \mathrm{F}= \\
\text { Fm }\end{array}$ \\
\hline
\end{tabular}

\section{Results and discussion}

According to the elaborated PCA results, shown in the graph in Fig. 1, the cumulative explained variance of components 1 and 2 is $79 \%$.

The observations are mainly spread along component 1; on the left, there are those relating to symptomatic leaves while on the right are the measurements of the leaves belonging to asymptomatic leaves. Near the intersection of the axes, the observations present belong both to the leaves of the SINTNO category and to the TEST vines. In the lowerleft quadrant, an area where there are only observations belonging to the TEST category is identified.

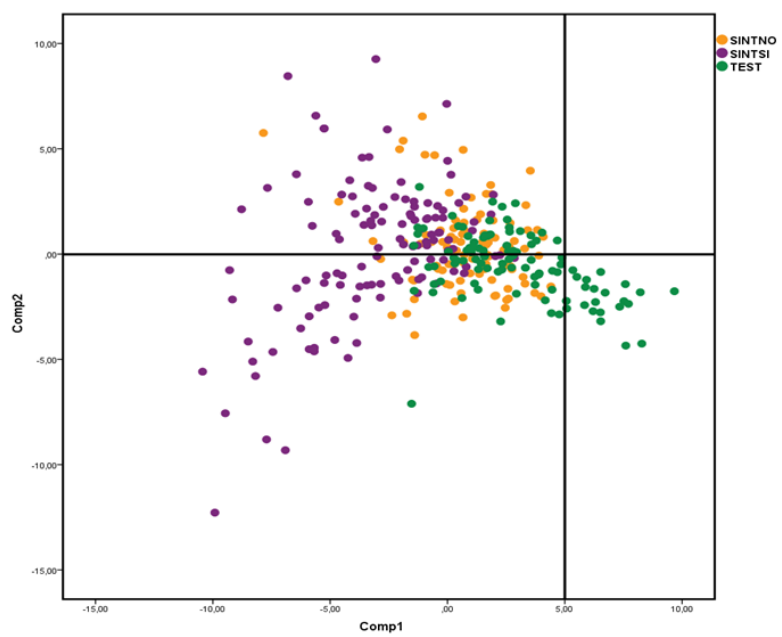

Fig. 1. PCA graph of components 1 and 2 explaining $79 \%$ of the variance.

Among the 23 parameters measured, 12 have a correlation coefficient with the first component higher than $85 \%$ in absolute value (Table 2).

Table 2. List of the measured parameters of chlorophyll fluorescence which have a $>85 \%$ correlation with PCA component 1 . The correlation coefficient (\%) is indicated for each parameter.

\begin{tabular}{|l|c|l|c|}
\hline Parameter & $\%$ & Parameter & $\%$ \\
\hline FM & 89,8 & PITOT & 87,4 \\
\hline Fv & 93,3 & $\mathrm{Vi}$ & 94,3 \\
\hline Area & 92,3 & $\mathrm{Vj}$ & 89,3 \\
\hline ETo & 91,8 & Mo & 94,3 \\
\hline RC/CS & 91,4 & Vo-j & 87,7 \\
\hline REo/ABS & 97,3 & Fv/F0 & 92,0 \\
\hline
\end{tabular}

The 12 selected variables were used for the discriminant analysis, obtaining the graph in Fig. 2. According to the results, the ideal healthy condition for photosynthetic efficiency (MODEL) is identified on the 
right side of the graph (in red), while on the left side are present the symptomatic leaves (in green), as well as an overlap zone that brings together the asymptomatic leaves (SINTSI and some TEST leaves - in purple and yellow).

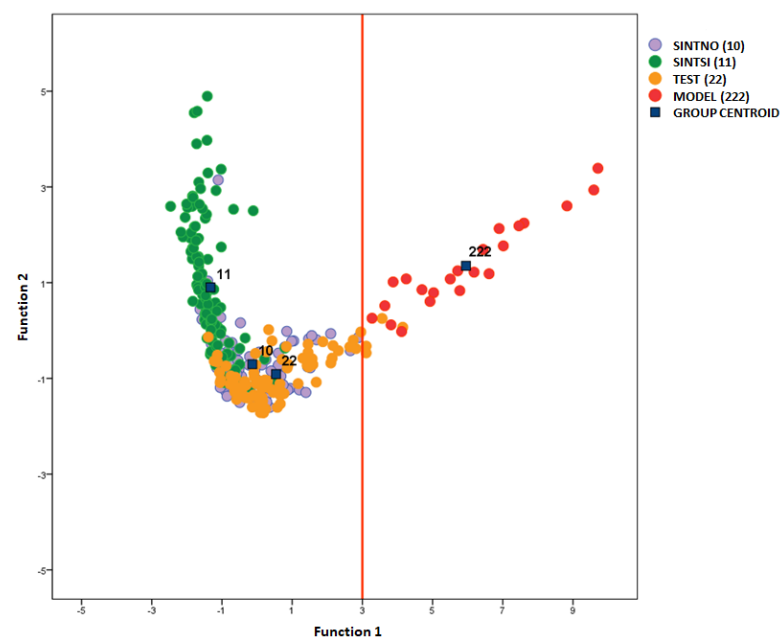

Fig. 2. Multivariate analysis using the parameters indicated in Table 2.

To carefully evaluate the differences between asymptomatic and test leaves during the fluorescence detection phase, it is necessary to observe the values of some parameters (Fig. 3). The graph shows the normalized values of some significant variables identified by the PCA. From this graph it is possible to extrapolate information about the parameters to be carefully evaluated during the fluorescence detection phase, noting the differences between asymptomatic and test leaves.

According to our results, it emerges that in symptomatic leaves the parameters $\mathrm{Vi}, \mathrm{Vj}$, Mo, and Vo$\mathrm{j}$, linked to the photosystem oxygen-evolving complex (OEC) functionality, assume high values, demonstrating leaf physiological difficulties.

In addition, observing the intermediate classes of TEST and SINTNO leaves, variations in the parameters $\mathrm{Vj}$ and $\mathrm{Vo}-\mathrm{j}$ can be seen, which can be interpreted as an alteration of the OEC efficiency and, therefore, a premonitory warning of esca disease infection. In the MODEL group, these parameters have minimal values, and vice versa the "positive" parameters (REo/ABS, PITOT, Fv/F0, ETo, RC/CS) reach maximum values, proving that, in this group, photosynthetic efficiency and leaf vitality are predominant.

\section{Conclusions}

The purpose of our study was to find one or more fluorimetric parameters useful for the early detection of esca disease in grapevine leaves. The measurements were carried out on a significant number of symptomatic (SINTSI), asymptomatic (SINTNO) leaves, and on vines not showing esca symptoms at least in the previous three years (TEST).

Our findings confirm that the presence of the esca disease complex causes a partial block at the "water splitting" level, and it is possible to get useful information for the predictive diagnosis of esca infection, even on asymptomatic leaves, when some fluorimetric parameters tend to increase (i.e., $\mathrm{Vj}$ ) and others (i.e., PITOT) tend to decrease, and intermediate values can represent the presence of the disease at different developmental stages.

The model presented will be tested again on an increasing number of leaf/vine combinations to validate on a larger scale the results already obtained.

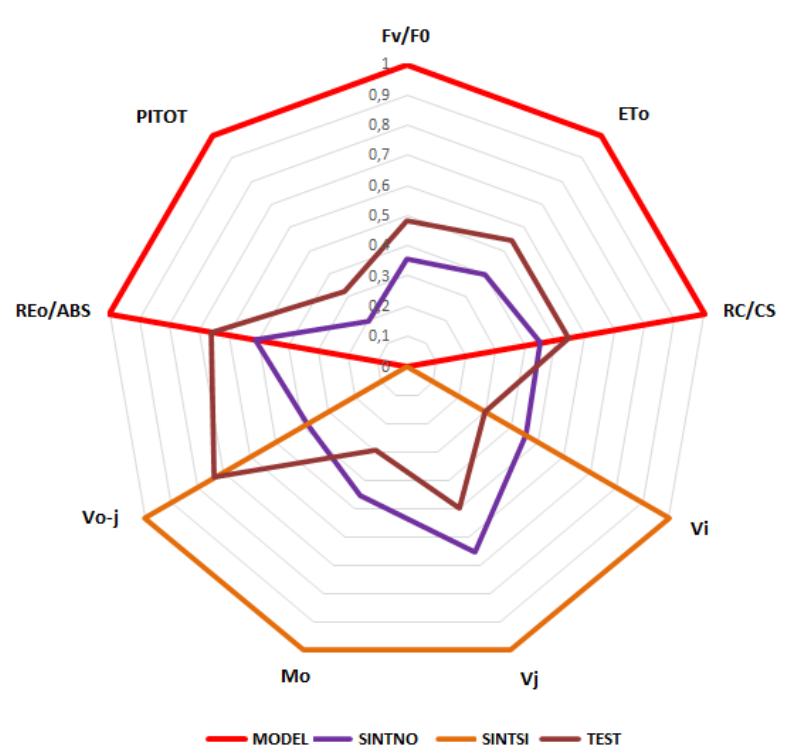

Fig. 3. Radar graph representation of the normalized average values of the relevant fluorimetric parameters for the early diagnosis of esca disease.

\section{References}

1. L. Mugnai, G. Surico, A. Esposito. Informatore Fitopatologico, 46 (1996).

2. L. Sparapano, G. Bruno, C. Ciccarone, A. Graniti. Phytopathologia Mediterranea, 39 (2000).

3. G. Surico, L. Mugnai, G. Marchi. Phytopathologia Mediterranea, 45 (2006).

4. L. Mugnai. Informatore Agrario, 15 (1999).

5. C. Bertsch, M. Ramírez-Suero, M. Magnin-Robert, P. Larignon, J. Chong, E. Abou-Mansour, A. Spagnolo, C. Clement, F. Fontaine. Plant Pathology, 62 (2013).

6. A.N. Petit, N. Vaillant, M. Boulay, C. Clément, F. Fontaine. Phytopathology, 96 (2006).

7. D. Christen, S. Schönmann, M. Jermini, R.J. Strasser, G. Défago. Environmental and Experimental Botany, 60 (2007).

8. G. Cavrini, S. Mignani, G. Soffritti. Esercizi di Analisi statistica multivariata risolti con SPSS per Windows. Edizioni Esculapio, Bologna (2006). 
9. B. Aragona. Tecniche di analisi multivariata. Alcune applicazioni con SPSS. Liguori editore, Napoli (2013).

10. Barbaranelli C. Analisi dei dati con SPSS. Le analisi multivariate. Edizioni LED, Milano (2006). 